\title{
UN LIBRO DE DUARTE
}

\section{POR JOSE RAFAEL LANTIGUA}

\section{Mariano Lebrón Saviñón}

La Universidad Nacional Pedro Henríquez Ureña pone hoy a circular un nuevo libro en el que se pondera la obra patriótica y apostólica de Juan Pablo Duarte, el más puro de los héroes de América, en el decir de Carlos Larrazábal Blanco; un Cristo de la Libertad, en atinada concepción deJ oaquín Balaguer; un hombre de fe y de gloriosos renunciamientos en el empinado Tabor del sacrificio.

Su autor es un joven de gran talento y un nombre consagrado ya en el quehacer de la cultura, como escritor y periodista admirables. Está ligado a nuestra Universidad desde sus días de estudios, realizados en su ámbito egregio de donde egresó con el título de Licenciado en Ciencias de la Educación, mención Letras, con el galardón de Cum Laude.

Desde Moca nos llega Lantigua. Es notorio, en el movimiento cultural dominicano, el aporte generoso de nuestras villas y ciudades donde la amodorrante quietud aldehueña no vence, $y$ acaso estimula, el temperamento de nuestras gentes. En un recuento exhaustivo hecho en este sentido nos asombraríamos de la intensa vida cultural que pueblos como San Pedro de Macorís - vívero de personalidades paradigmáticas - Azua, ó La Vega, donde el movimiento de los Los Nuevos, antes de La Poesía Sorprendida, bajo el impulso vivaz y selectivo de Rubén Suro, estremeció los cimientos literarios del país en días de riesgosos aconteceres. Ejemplos al desgaire nos dicen que Monte Cristi -es la cuna de Manuel Rueda y en un pueblo de aparente rezago, como Pimentel, nació, creció y se formó, Manuel Mora Serrano, gloriosa juventud orientadora.

Moca, la cuna de Lantigua, en el mismo riñón del Cibao, mártir y épica, sufrida y heróica, ha dado también fecunda constelación de hombres ilustres. Acaso la caricia feral de su hermosa naturaleza la hace pródiga y la tragedia secular de nuestras contingencias históricas, le da esa reicedumbre que comparta su historial de hechos epopéyicos. J uan Antonio Alix, el 
Cantor del Yaque; Max Guzmán, el mago de las criollas acariciantes y románticas; Aida Cartagena Portalatín, paradigmático exponente de la mujer dominicana y el doliente y olvidado Manuel Valerio son representantes mocanos de nuestra cultura.

Moca tiene también su historiador : J ulio Jaime J ulia, abnegado y modesto, como las flores de buenas tardes que se apagan expontáneamente cuando irradia el sol. Cada ciudad y cada región debiera tener su historiador como E. O. Garrido casi llegó a serlo del Sur amado por él en lo profundo de su entraña vital hoy quieta en el arcano de la muerte o como puede llegar a serlo Mañón Arredonde de nuestro Santo Domingo, aún a despecho de Luis Alemar.

Dos jóvenes ejemplares, J osé Rafael Vargas y J osé Rafael Lantigua, con ejemplar pertinacia, propugnan hoy por empinarse en el alcor de la cultura dominicana.

Lantigua, cuyo libro "Hacia una revalorización del ideal duartiano "ponemos a circular hoy se nos aparece con una prosa diáfana, pulcra, directa, apasionante. Este libro, según consta en un aclarando oportuno, "fue concluido por su autor en noviembre de 1976, Centenario de la muerte del patricio Juan Pablo Duarte y presentado al Concurso Nacional auspiciado por el Instituto Duartiano en 1977."

Fue, desde luego, el ganador del primer premio, que le otorgó un jurado que formaron los distinguidos intelectuales : Emilio Rodríguez Demorizi, Vetilio Alfau Durán y Pedro Troncoso Sánchez. El galardón le fue ofrecido, según palabras de Troncoso Sánchez: "Por su alto y rico valor conceptual y por la demostrada capacidad de investigación y análisis del autor."

Lantigua se empapa de la vida de Duarte, abreva en el ánfora de su ideal, pero se somormuja, también en el agua inquietante de su agonia, de esa agonía desgarrante $y$ dolorosa en impiadoso lecho de casi un año, mientras llevaba en el ansión del alma, como un peso implacable, el recuerdo de la patria cuya lejanía añorada le proporcionó, según Eugenio María de Hostos, apóstol mágico de la enseñanza, catorce años de ilusoria agonía mortal.

Cada apartado de su libro es una joya de vehemenciales extroversiones de su alma. A veces da a su prosa tonos elegíacos, $y$, con efecto, ya en el Introito expresa: "La vida de Duarte es una vida preñada de angustias, saturada de irónicos desprecios, turbada por desconsuelos y agravios, azotada por vendavales de la maledicencia y la envidia." Esto, enfocado asi, enfatiza la idea que yo expresé una vez de que la vida de Duarte es un drama de Esquilo, en lo más estremecedor de la sublimidad trágica.

Un Prometeo fue; amarrado a la roca frente a la eternidad, en un cruel e impiadoso martirio, por el sólo delito de darle a los dominicanos el fuego de la fe, del ideal y de la libertad. 
Empero fue mansa su rebeldía y no colérica, para hacer más digna y conmovedora la increible decisión de su renunciamiento.

$J$ osé Rafael Lantigua es justo y noble, radicalmente dominicano -de pensamiento $y$ de sangre-, con este libro, casi un opúsculo, que resulta un monumento ideal a la memoria del héroe y del apóstol; ponderándolo en la verdadera magnitud de su grandeza nos dice:

"Parecería entonces, a la luz de las afirmaciones precedentes, que la vida del Fundador de la Nacionalidad Dominicana no es más que un trágico devenir, salpicada de inexplicables desgracias, y, por tanto, consumida en el estrecho círculo trazado por el peso del infortunio. Una vida así, maltratada, sentenciada a un destino cruel, sólo puede dar cabida a una mentalidad vulnerada, de realizaciones frustradas y de desevelos míticos. Pero no.

En la historia dominicana y el haber de los grandes forjadores de nacionalidades, no hay mayor triunfo sobre la adversidad, ni mayor temple frente a las ingratitudes del ambiente.

Ese es, precisamente, el temple espartano - algo de Prometeo y de Cristo - que hemos ponderado en la obra de Duarte y que nos es dable destacar en nuestro héroe.

"La gran lección de Duarte - sigue Lantigua- se encuentra precisamente en esa vida que corrió pareja en palabras y hechos, en esa existencia, arriesgada que se conjugó con el más preclaro pensamiento patriótico, $y$ en la que debemos buscar los dominicanos la fuente para impulsar las más dinámicas y constructivas tareas de engrandecimiento patrio.

Esa vida - ejemplo de Duarte es paradigma de fe en nuestro porvenir."

Lantigua agota su tema con mesura pero sin ocultar el temblor emocional de su pensamiento. No la exageración ditirámbica. Los elogios desmensurados, la exorbitada ponderación es muestra de lugareña estrechez, de angosta visión terral. Pero la exaltación vehemente no lo es. Cuando se hipertrofian los elogios a seres vivos - cuya honda no ha llegado a su meta,- como en el caso de caudillos prometedores de bienes sin cuento, entonces es bajeza y misérrima exteriorización del alma : pero a los héroes hay que crearles pedestales de admiración cuando acrecen su imagen con la perspectiva de distancia que da la muerte.

Paradójicamente mientras todavía se le ponen reparos a la vida de Duarte, son voces exóticas las que lo sumergen en la ría anchurosa de sus elogios. Sumner Welles nos lo presenta asi en uno de los capítulos de "La viña de Naboth" : 
"En la larga lista de eminentes patriotas de la América que han vivido y han muerto para dar vida a la Libertad del Nuevo Mundo,J uan Pablo Duarte ocupa y ocupará siempre un puesto prominente."

$Y$ agrega, el historiador norteamericano, deslumbrado por el raro fulgor de nuestro héroe:

- "Desilusionado por la ingratitud más grosera, desanimado por la rapidez con que vio los ideales por los que se había desvivido, sumergidos bajo la ola de corrupción y bajas ambiciones, Duarte desaparece del escenario dominicano, al cual debía volver en visita fugaz, con el fardo de sus tristezas, pero con inextinguible fe en el destino de su amado pueblo. QQué admirable figura de verdadera grandeza, de abnegación inigualable! Más, los ideales acariciados por Duarte son imperecederos; la voz espiritual de Duarte no se ha callado; en años posteriores, en los momentos de calma al intermitir el fragor de las luchas fratricidas o asomar la hosca faz del peligro exterior, la lucidez dominicana ha oido repercutir la voz de Duarte señalando la senda de la salvación. La doctrina inspirada por Duarte ha guiado a su pueblo por entre sirtes y escollos hasta un porvenir mejor."

El escritor y humanista italiano, Salvatore Lois, cuando conoció la vida de Duarte, seducido por tan fascinante personalidad, escribió un ensayo : "J uan Pablo duarte, cavaliere della humanita" donde analiza diferentes aspectos de su trayectoria luminosa.

También el poeta cubano Rafael Estenger acerca a nuestro Duarte, en unos Campos Eliseos ideales, a Hostos y Martí, en su obra "La vida gloriosa y triste deJ uan Pablo Duarte".

Pero es J osé Angel Buesa, el poeta del amor, quien con ocasión del año centenario de Duarte, le rindió un homenaje mejor con su largo "Canto a Duarte" que concluye con estas nueve estrofas :

J uan Pablo Duarte, general del viento:

Te estoy cantando para merecerte, $y$ canto que no hay muerte en una muerte que resucita en otro nacimiento

$Y$ ante tí, que te fuiste $y$ no te has ido, sólo ha de ser el canto del poeta como el lento rumor de una carreta por los cañaverales del olvido Y tú estarás de pie, limpia la frente, luminoso en la luz,J uan Pablo Duarte, 
pero no lejos, en un mundo aparte sino como uno más entre tu gente.

Así estás, primavera de otro modo, plenitud germinal que no descansa, así, de pie, con tu sonrisa mansa, con tu ademán de bendecirlo todo.

$Y$ ante tu bendición todo florece, con su fe simple y su virtud sencilla, como crece por dentro la semilla sin saber que es semilla ni que crece.

General de la pena que se calla, cristianamente pobre en el camino; general del pupitre campesino que es tu más noble campo de batalla.

Yo estoy contigo, apóstol trinitario, $Y_{0}$, que tengo de luto mi bandera $y$ te ofrezco un laurel, a mi manera, para la gloria de tu centenario

$Y$ para ser igual que el campanero que repica lo triste y lo entusiasta, con mi 20 de mayo a media asta canto tu 27 de febrero.

Y canto la alegría de cantarte bajo este cielo tuyo y casi mío, General de la lluvia y del rocío hermano de Martí,J uan Pablo Duarte. 